\title{
Awareness of Paddy Farmers on Climate Change and Its Impact on Crop Production: A Study in Kalthota Irrigation Scheme
}

\author{
Basnayake B.M.R.L. ${ }^{1}{ }^{*}$, Weddagala W.M.T.B. ${ }^{1}$, Mahaliyanaarachchi R.P. ${ }^{1}$, \\ Sivasankar P. ${ }^{1}$, Elapata M.S. ${ }^{1}$ \\ ${ }^{1}$ Department of Agribusiness Management, Faculty of Agricultural Sciences, Sabaragamuwa \\ University, Sri Lanka \\ *ruwinibasnayake@gmail.com
}

\begin{abstract}
Agriculture is one of the most important sectors in the Sri Lankan economy and contributes $7.9 \%$ for the national GDP. As the staple food, paddy production is playing a key role in the agricultural sector, contributing $0.9 \%$ to national GDP. However, Sri Lanka as a small island is more susceptible to most of the climatic change impacts like increasing temperature of land and sea surface and changes of the rainfall pattern, extreme drought and flood conditions. Nevertheless the agriculture sector ishighly sensitive to climate change in both short and longterm ways and it is important to pay attention on the impact of climate change on the agriculture sector in Sri Lanka.The study assessed the awareness of recent changes in the extreme climatic events and its impact on paddy production in the Kalthota irrigation scheme which is recorded as the second largest paddy producer in Rathnapura district and the highest water consuming area for paddy cultivation in Sri Lanka. It further explored the perception of paddy farmers on the impact of climate change, existing adaption methods and limitation factors that affected the adaption measures.Simple random sampling technique was used to select 63 paddy farmers and primary data were collected using structured questionnaires and direct observations. Journal articles and reports of Meteorology Department were used as secondary data sources. The collected data were analysed by using descriptive statistics and correlation analysis. The results indicated that majority of the paddy farmers $(92.1 \%)$ were aware of the climatic change effect on the crop yield, however, only $38.1 \%$ were practicing different adaption methods such as using drought-resistant varieties and changing harvesting time.However the results also indicated(31.7\%) that the farmers have an inclination on performing various spiritual activities believing that these supernatural practices have an impact on changes of climate and adaption for the rainfall pattern changes based on their experience. Inadequate information on adaptation practices and income options act as barriers in shifting to different adaption measures. Nevertheless, the study revealed that even though the farmers are aware on the detrimental effects of the climate change, adapting different strategies to mitigate climate is not taken in to account. The study also revealed that the responsible authorities should implement different strategies to educate farmers on the various adaption techniques.
\end{abstract}

Keywords:Climate change, Agriculture, Paddy, Adaptation, Sri Lanka

Proceedings of the $22^{\text {nd }}$ International Forestry and Environment Symposium 2017 of the Department of Forestry and Environmental Science, University of Sri Jayewardenepura, Sri Lanka 